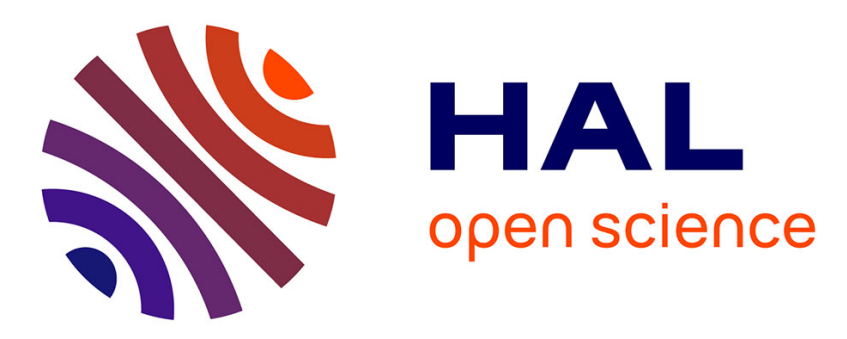

\title{
Cardiac electronic implantable devices after tricuspid valve surgery
}

Raphaël P Martins, Vincent Galand, Christophe Leclercq, Jean-Claude

Daubert

\section{> To cite this version:}

Raphaël P Martins, Vincent Galand, Christophe Leclercq, Jean-Claude Daubert. Cardiac electronic implantable devices after tricuspid valve surgery. Heart Rhythm, 2018, 15 (7), pp.1081-1088. 10.1016/j.hrthm.2018.01.015 . hal-01812224

HAL Id: hal-01812224 https://hal-univ-rennes1.archives-ouvertes.fr/hal-01812224

Submitted on 20 Sep 2018

HAL is a multi-disciplinary open access archive for the deposit and dissemination of scientific research documents, whether they are published or not. The documents may come from teaching and research institutions in France or abroad, or from public or private research centers.
L'archive ouverte pluridisciplinaire HAL, est destinée au dépôt et à la diffusion de documents scientifiques de niveau recherche, publiés ou non, émanant des établissements d'enseignement et de recherche français ou étrangers, des laboratoires publics ou privés. 


\section{Cardiac electronic implantable devices after}

\section{2 tricuspid valve surgery}

3

4

5

6 7

8

9

10

\section{Authors:}

Raphaël P. Martins, MD, PhD ${ }^{1,2,3}$ Vincent Galand, MD, ${ }^{1,2,3}$ Christophe Leclercq, MD, PhD, 1,2,3 Jean-Claude Daubert, MD, ${ }^{1,2,3}$

\section{Working group address:}

1 CHU Rennes, Service de Cardiologie et Maladies Vasculaires, Rennes, F-35000, France

2 Université de Rennes 1, CIC-IT 1414, F-35000, France

3 INSERM, U1099, Rennes, F-35000, France

\section{Corresponding author:}

Raphaël P. Martins, Service de Cardiologie et Maladies Vasculaires, CHU de Rennes, 2 rue Henri Le Guilloux, 35000 Rennes, France. Tel: + 33299282 507, Fax: +33 299282 529, email : raphael.martins@ chu-rennes.fr

Short title: Device implantation after tricuspid valve surgery

\section{Word counts: 5508}

Type: Contemporary Review

\section{Conflicts of interests: None.}




\section{$24 \underline{\text { Abstract }}$}

25 The demand for tricuspid valve (TV) surgery has increased continuously these last years.

26 Recent registry data have confirmed that TV repair or replacement carry an increased risk of

27 conduction disorders requiring permanent pacemaker implantation, specifically for patients

28 having multivalve surgery. The implantation of an endocardial right ventricular lead in those

29 patients may impair TV function, and some other approaches may be discussed to avoid

30 traversing the valve. This contemporary review describes the different options currently

31 available for patients requiring pacemaker or defibrillation leads implantation after TV 32 surgery.

33

34 Keywords

35 Tricuspid valve; Implantation; Pacemaker; Implantable Cardioverter-Defibrillator; Surgery 


\section{INTRODUCTION}

Following the evolution of clinical indications, ${ }^{1,2}$ the demand for surgery of the tricuspid valve (TV) has increased continuously. In the United States, the annual number of TV surgical procedures almost tripled between 2000 and 2010, the majority combined with leftsided valve surgery. ${ }^{3}$ Treatment options include TV repair and TV replacement with a bioprosthesis or a mechanical valve when repair is not feasible ${ }^{1}$. Recent registry data have confirmed that TV surgery carries an increased risk of conduction disorders leading to permanent pacemaker implantation. ${ }^{4,5}$ The risk is doubled among patients undergoing multivalve surgery. The implantation of cardiac implantable electronic devices, mostly pacemakers after TV surgery involves technical difficulties which must be known to the implanters in order to select the best technical option in the individual patient. Several approaches have been reported: epicardial leads, standard endocardial leads, his-bundle pacing, leadless pacing, or coronary sinus leads. This paper reviews the current trends in tricuspid valve surgery, the need for permanent pacing after surgery including clinical indication and timing, and the technical options for device implantation, discussing the advantages and disadvantages of each technique. Practical recommendations are provided.

\section{TRICUSPID VALVE SURGERY: CURRENT TRENDS}

Based on expert opinion (Level of evidence: C), the 2017 ESC $^{1}$ and 2014 AHA/ACC ${ }^{2}$ guidelines for the management of patients with valvular heart disease gave a class I recommendation for TV surgery for i) patients with severe primary or secondary tricuspid regurgitation (TR) undergoing left-side valve surgery; ii) symptomatic patients with severe isolated primary TR without severe right ventricular (RV) dysfunction; iii) symptomatic patients with severe tricuspid stenosis (TS) or patients with severe TS undergoing left-side valve surgery. In addition, surgery should be considered (Class IIa) for iv) patients with moderate TR undergoing left-side valve surgery patients; v) patients with mild to moderate secondary TR with tricuspid annular dilatation or prior evidence of right heart failure undergoing left-side valve surgery; vi) patients with asymptomatic or mildly symptomatic severe isolated primary TR and progressive RV dysfunction. As TV disease is rarely isolated, most surgical procedures are combined with left-side valve surgeries.

Treatment options for TV surgery include valve repair with or without annuloplasty ring and in case of unrepairable valvular lesions or late failed repair, TV replacement with a bioprosthesis or a mechanical valve. The two types of valves have similar long-term clinical outcome. ${ }^{6-9}$ In clinical practice, like for left-heart valves, bioprostheses are generally preferred 
in patients over 65 years and mechanical valves in younger patients with need to continuous anticoagulation. Temporal trends of TV surgery were recently analysed in the STS (Society of Thoracic Surgeons) database. ${ }^{3}$ Over the last decade, 54735 patients underwent TV surgery in the US. The annual number of TV surgeries almost tripled between 2000 and 2010, the majority combined with other major surgical procedures $(85.7 \%)$, mainly mitral valve surgery. The proportion of valve repairs increased from $84.6 \%$ in 2000 to $88.9 \%$ in 2010 with a parallel decline in TV replacements. The most common type of valve repair was annuloplasty alone $(75.5 \%)$ and most TV replacements were performed using bioprostheses $(81.5 \%)$. Despite increasing age and comorbidity, there was a gradual decrease in operative mortality from $10.6 \%$ to $8.2 \%$ during the study period, although concomitant procedures involving multiple valves or $\mathrm{CABG}$ were associated with an increased risk of mortality compared with isolated TVS.

\section{NEED FOR PERMANENT PACING AFTER TRICUSPID VALVE SURGERY}

\section{Trends and indication of permanent pacemaker implantation}

Tricuspid valve surgery carries a significant risk of conduction disorders requiring permanent pacemaker implantation (PPI). The implantation rate tended to decrease over time from 13$22 \%$ before $2000^{4}$ to $5-11 \%$ in the recent years, ${ }^{10}$ but rates as high as $27 \%$ have been recently described after TV replacement. ${ }^{11}$ Multivalve surgery, ${ }^{4,5}$ redo-TV surgery ${ }^{12}$ and the use of a ring annulus for TV repair ${ }^{10,13}$ are independent surgical predictors of PPI need. In the study by Koplan, ${ }^{4}$ TV surgery doubled the risk of PPI in patients with multivalve surgery. Similar observations were recently reported in a large UK multicentre registry of more than 135,000 patients with valve replacement. Using single aortic valve replacement as reference, hazard ratio for PPI was $2.22(95 \% \mathrm{CI} 1.40-3.53, \mathrm{p}<0.001)$ for multivalve surgery including TV replacement, compared to $1.52(95 \% \mathrm{CI} 1.40-1.65), \mathrm{p}<0.001)$ without TV replacement. $^{5}$ (Figure 1). In the whole registry population, age, male gender, renal impairment and heart failure were identified as independent clinical predictors of PPI requirement. However, these clinical risk factors have not been found in specific populations of TVS patients. In the same groups, no preoperative ECG characteristics were identified to predict postoperative PPI need. ${ }^{10,13}$

The leading ECG indication for PPI after TV surgery is atrial fibrillation with slow ventricular response $\left(57 \%{ }^{10}\right)$, followed by complete heart block $(28 \%)$ and sinus node dysfunction. Indeed, most of the patients undergoing TV surgery are in permanent atrial fibrillation 
$\left(76 \%{ }^{10}\right)$, explaining why a majority of TV surgery patients needing PPI are implanted with a single-chamber VVI/VVIR device $\left(75 \%{ }^{10}\right)$

\section{Timing of PPI: immediate versus late implantations}

To date, only one single study brought insights about the timing of PPI after TV surgery. ${ }^{10}$ Fifty four percent of the pacemakers were implanted before hospital discharge after a minimum follow-up time of 5 days; most of these patients needed temporary pacing immediately after the surgery. The other $46 \%$ patients had delayed implantation up to 8 years post-operatively (Figure 1). A similar increased risk of late conduction disturbances after TV surgery compared to other valve interventions was also shown in the UK registry. ${ }^{5}$

Some teams, mainly in the US, made the choice of immediate PPI using epicardial leads in case of perioperative heart block. In the STS database, $4.2 \%$ of the patients with TV repair and $5.6 \%$ with TV replacement received permanent epicardial pacemaker at the operative time. $^{3}$ This strategy is debatable since it is well known that a significant proportion of patients with PPI after cardiac surgery are no longer PM-dependent at long-term follow-up. The proportion is higher for patients implanted for sinus node dysfunction (60-70\%) than those implanted for AV block (0-35\%). ${ }^{14}$ Such observation was also demonstrated in the specific group of TVS patients where up to $65 \%$ were no longer PM-dependent during long-term follow-up. ${ }^{10,11}$ This observation is an additional argument for delaying PPI if possible. Thus, it seems reasonable to apply to TV surgery patients the general guidelines recommendation on PPI indications after cardiac surgery, i.e. a period of clinical observation up to 7 days to assess whether the rhythm disturbance is transient and spontaneously resolves. Temporary epicardial leads should be maintained during this observation period. However, in case of complete AV block with low rate escape rhythm, this observation period can be shortened since resolution is unlikely (Class I, level of evidence C). ${ }^{14}$

\section{Long-term outcomes}

There are very few data in the literature on long-term clinical outcomes after PPI in TV surgery patients. In the series of Jokinen et al on 136 patients with a mean follow-up time of $7.9+4.1$ years, survival was better in patients with pacemaker implantation than in patients without pacemaker $(\mathrm{P}=0.05) .{ }^{10}$ However, PPI was significantly associated with a higher incidence of cerebrovascular events (stroke or transient ischemic attack) and of worse functional status (NYHA Class III-IV). 

SURGERY

139

\section{Pacemaker implantation in patients with TV surgery}

Five different options can be discussed i) implant epicardial leads; ii) implant a standard transvenous RV lead; iii) implant a parahissian lead for His-bundle pacing (HBP); iv) implant a coronary sinus lead for left ventricular (LV) pacing only; and v) implant a leadless pacemaker.

\section{Epicardial pacing}

Data regarding epicardial pacing after TV surgery in adults are scarce. Indeed, most of the available data are about epicardial device implantation in patients after congenital heart disease repair. Although epicardial devices are efficient to ensure pacing, the reliability of endocardial leads has been shown to be superior compared to epicardial systems. ${ }^{15,16}$ This is particularly true if patients already had open-heart surgeries, since operators may have a hard time to find a portion of ventricle with acceptable pacing thresholds. Although this option has been widely used in the STS registry, ${ }^{3}$ perioperative implantation of permanent epicardial pacing leads should be reserved for very specific cases of immediate AV block with very low probability of secondary resumption (see paragraph Timing of PPI). An example of epicardial pacemaker implanted after tricuspid valve replacement is shown in Figure 2A.

\section{$R V$ transvenous leads}

Cardiac implantable electronic device leads can interfere with the function of native tricuspid valves, leading to a significant morbidity and mortality through hemodynamic impairment. In a series published by the Mayo Clinic group, 41 device recipients required TV surgery for severe TV regurgitation caused by previously placed RV transvenous pacemaker or ICD lead. ${ }^{17}$ All patients were found to have morphologically normal TV with malfunction caused by the lead, mostly lead adherence or impingement. The TV was repaired or replaced, and the lead removed or positioned and sutured in the posteroseptal or anteroposterior commissure. Recent data suggest that PM leads are associated with a higher risk of TV regurgitation grade 3-4 after adjustment for LV systolic dysfunction and pulmonary hypertension, and that PMrelated regurgitation was associated with a $40 \%$ increased mortality. ${ }^{18}$ Thus, a thorough consideration has to be made in the decision of implanting transvenous RV leads. 
The mechanisms leading to lead-induced TV dysfunction are various, either mechanical (TV obstruction, perforation or laceration; lead adherence due to fibrosis causing incomplete TV closure; lead entrapment in the TV apparatus) or functional (pacing-induced dyssynchrony leading to myocardial dysfunction and TV annular dilatation), ${ }^{19}$ and requiring a specific management based on lead removal/relocation/replacement associated with TV repair/replacement if needed, depending on clinical and echocardiographic data. ${ }^{20}$

Data regarding the interaction of RV transvenous leads with TV apparatus after valvular repair or replacement are scarce and controversial. Mazine et al reported their experience on 791 patients with TV repair between 1997 and 2008, 176 of them having or requiring a subsequent pacemaker implantation. ${ }^{21}$ The presence of a transvenous pacemaker was found to be an independent risk factor for recurrence of TR during follow-up. The presence of a transvenous lead was also found to be a significant independent predictor of late mortality. Conversely, Eleid et al did not find any clear evidence of increased risk of post-operative severe TR in a cohort of 58 patients who underwent a bioprosthetic TV implantation prior to PM/ICD transvenous lead implantation. ${ }^{22}$ Although more data would be required to clarify the safety of such method, transvalvular lead implantation may appear an acceptable approach for patients after TV repair or with a bioprosthetic TV or/and requiring a permanent pacemaker or defibrillator placement. Examples of transvenous lead implantation after bioprostheic valve replacement or repair are shown in Figure 2 (Panel B and panels C and D, respectively).

However, we firmly do not recommend, even done and published, ${ }^{23}$ positioning a RV transvenous lead through a mechanical valve due to a high risk of complications, including, obviously, the risk of lead fracture and valve obstruction.

\section{His-bundle pacing}

Compared to ventricular pacing, HBP is a more physiologic form of pacing supposed to preserve normal electrical activation of the ventricles and prevent ventricular dyssynchrony. ${ }^{24}$ This could be an interesting alternative for treating post-TVS AV blocks, especially as the conduction disorder is nodal in the majority of cases. HBP has been described to be feasible in a majority of patients after prosthetic valve surgery, ${ }^{24}$ but in the series published so far, only 10 patients with TV rings were included and none with TV replacement. From a technical point of view, the TV ring may act as a radiographic marker of the his-bundle and facilitate the identification of the successful site. Interestingly, successful sites of HBP appeared to be at an average distance of $19 \mathrm{~mm}$ from the TV ring. ${ }^{24}$ Further studies will be required to analyze the safety and efficacy of HBP specifically in patients after TV surgery. 
Before the advent of transvenous CRT in late 90s', few manuscripts reported cases of permanent ventricular pacing through coronary veins, either due to inadvertent placement of the "RV" lead into the middle cardiac vein with a revised diagnosis obtained from paced RBBB pattern and from the chest-X ray in sagittal view, ${ }^{25-27}$ or with a deliberate CS positioning due to inaccessible RV in patients with congenital heart diseases ${ }^{28-30}$ or after TV replacement. $^{26,31,32}$

Since CRT emerged as a cornerstone therapy for heart failure patients, rare supplementary data have been published in the literature regarding CS pacing after TV surgery. Only one small series of 17 patients (11 TV repairs and $6 \mathrm{TV}$ replacements, including 2 mechanical ones) was recently published. The time interval for PM implantation after TV surgery was around one week. Pacing threshold at implantation was $1.9 \pm 0.3 \mathrm{~V}$ and remained stable after a 2-year follow-up. ${ }^{33}$ Due to the right atrial dilatation and resulting malposition of the CS ostium, CS catheterization and lead placement may be more challenging in this specific situation compared to typical CRT patients.

The long-term effects of VVI pacing using only one single LV lead are not very well known. In observational studies in CRT patients, LV pacing with a single lead seemed to have similar clinical efficacy and safety compared with biventricular pacing. ${ }^{34}$

However, there is currently no data regarding the consequences of lateral or postero-lateral LV-only pacing in patients with TV regurgitation-induced pre-existing RV dysfunction and/or pulmonary hypertension. The risk of pacing-induced inverted mechanical dyssynchrony would be theoretically possible, although not clinically demonstrated. Thus, targeting the great cardiac vein might be a good option in such patients, since QRS duration is often shorter and ventricular activation sequence is more homogeneous when pacing from this position (Figure 3). In every case, the CS lead should be positioned in a stable and harmless position.

\section{Leadless pacemaker}

232 There are currently no large data about the safety and efficacy of leadless pacemakers in patients after TV surgery. In the Nanostim registry, Reddy et al report that $6(1.1 \%)$ out of the 526 patients included had a history of TV repair or bioprosthetic replacement, but, to the best of our knowledge, no specific data was reported yet, ${ }^{35}$ while in the Micra registry, Reynolds et al do not specify if any of the patients included had prior TV surgery. ${ }^{36}$ To date, cases reporting a Micra implantation after TV repair $^{37}$ and TV bioprosthesis surgery ${ }^{38,} 39$ were 
reported (Figure 4). The procedures were straightforward, with no complications, and patients did not have any valvular dysfunction after the intervention.

To note, leadless pacing can only provide single-chamber ventricular pacing, which can be a limitation for those patients necessitating dual-chamber pacing. However, a high proportion of patients after TV surgery is in atrial fibrillation and will not require the implantation of an atrial lead. Lastly, one major concern of this technique would be the issue of damaging a newly repaired/replaced TV with the delivery tools. Thus, although attractive, this approach will need further evidence regarding its safety profile and the potential need to have a postoperative blanking period, before being largely used in clinical practice.

\section{ICD implantation in patients with TV surgery}

Four approaches can be discussed for ICD implantation after TV surgery.

The implantation of an epicardial ICD can be proposed, but is of high operative risk in frail patients. A transvenous ICD RV lead implantation may be preferred for those patients after TV repair or bioprosthetic valve replacement (Figure 5, panel A).

Some cases initially reported the safety and efficacy of ICD lead implantation in the coronary sinus (Figure 5, panels B and C), ${ }^{40,41}$ confirmed by a small study of 6 patients with congenital heart diseases contra-indicated for transvenous RV lead implantation. Lopez et al ICD lead was placed in the middle-cardiac vein, with a defibrillation threshold safety margin of at least $10 \mathrm{~J}$ in all patients. ${ }^{42}$ During follow-up, 1 patient was successfully shocked and 2 had successful antitachycardia pacing and the remaining ones. The only concern of such approach remains the extractability of an ICD lead, with a coil positioned in a tributary vein of the coronary sinus. Further studies will be needed to prove the safety of such approach.

Alternatively, an approach associating the implantation of a ventricular sensing lead in the CS and a defibrillation lead floating free in the inferior vena cava has been described in a patient with Ebstein's disease and a bioprosthetic heart valve (Figure 5, panel D), with a stable defibrillation threshold after 1-year follow-up. ${ }^{43}$

To avoid the potential future issue of TV dysfunction and lead extraction, an attractive option could be the implantation of a subcutaneous ICD (S-ICD) if the patient is eligible and has no indication for pacing (Figure 5, panels E and F). Indeed, S-ICD eliminates the need for vascular access, and therefore, the risk of lead-induced TV dysfunction. ${ }^{44}$ Evidences regarding the safety and efficacy of S-ICD are increasing, ${ }^{45-47}$ and this major breakthrough in the defibrillation topic could be considered as a perfect alternative for patients after TV surgery, as described in a case recently published. ${ }^{48}$ 


\section{The problem of patients with pre-existing transvenous RV leads}

274

275

In case of a pre-existing RV transvenous lead in a patient requiring TV replacement, two different options may be discussed. First, surgeons may choose to cut the lead, unscrew and remove the distal part of the lead, and leave the proximal part for a percutaneous extraction. Pacing is ensured by implanting an epicardial pacemaker. This solution is suboptimal since extractability of the remaining lead is hampered by the impossibility of using standard dedicated techniques (wires, laser, mechanical tools, ...). Alternatively, a conservative technique can be used, by removing the native TV, and position the prosthesis in the annulus, leaving the RV lead undisturbed outside the TV. ${ }^{17,49,50}$ The main concern of this technique would be the occurrence of a device infection. Indeed, percutaneous extraction would be theoretically impossible, and such patients would require a surgical approach for lead removal. The same approach can be used for patients with pre-existing ICD leads, although the risk of lead fracture and subsequent inappropriate therapy may be a serious issue.

In case of TV repair not requiring a replacement, the technique recently described by Raman can be used, where ICD or PM leads are mobilized and detached if needed from the TV leaflets, then repositioned in the cleft between the septal and the inferior/posterior leaflets with suture approximation of the leaflets above the cleft, and eventually an annuloplasty can be performed if needed. ${ }^{20,51}$

\section{PRACTICAL RECOMMENDATIONS - CONCLUSION}

The annual number of TV surgeries is continuously increasing, and some of these patients will require immediately after the surgery or later on a PM or ICD device implantation. Therefore, one has to be prepared to consider all the benefits and drawbacks of the potential options in these situations, aiming to obtain a safe and efficient pacing/defibrillation without damaging the surgical effort. We propose the following recommendations (Tables 1 and 2):

- In case of immediate AVB with a low chance of AV conduction resumption (multivalve surgery, ${ }^{4,5}$ redo-TV surgery ${ }^{12}$ and the use of a ring annulus for TV repair $^{10,13}$ ), an epicardial pacemaker should be implanted.

- If the AVB occurs late, the preferred options in patients with repaired/bioprosthetic TV would be to implant either a regular transvenous lead or a CS lead. Although assumed to be an attractive solution, leadless PM implantation will require further safety evidence before it can be largely used in this type of patients. In patients with 
mechanical prosthesis, the only options are the implantation of an epicardial PM or a regular PM with a CS lead.

- For patients requiring ICD implantation after TV surgery, we recommend implanting a $\mathrm{S}$-ICD if the patient is eligible and does not require pacing. Otherwise, a regular RV transvenous lead should be implanted in patients with repaired/bioprosthetic TV, while an epicardial ICD should be proposed for those with mechanical prosthesis.

\section{REFERENCES}

1. Baumgartner H, Falk V, Bax JJ, et al. 2017 ESC/EACTS Guidelines for the management of valvular heart disease: The Task Force for the Management of Valvular Heart Disease of the European Society of Cardiology (ESC) and the European Association for Cardio-Thoracic Surgery (EACTS). Eur Heart J. 2017.

2. Nishimura RA, Otto CM, Bonow RO, et al. 2014 AHA/ACC guideline for the management of patients with valvular heart disease: executive summary: a report of the American College of Cardiology/American Heart Association Task Force on Practice Guidelines. J Am Coll Cardiol. 2014;63:2438-2488.

3. Kilic A, Saha-Chaudhuri P, Rankin JS, Conte JV. Trends and outcomes of tricuspid valve surgery in North America: an analysis of more than 50,000 patients from the Society of Thoracic Surgeons database. Ann Thorac Surg. 2013;96:1546-1552; discussion 1552.

4. Koplan BA, Stevenson WG, Epstein LM, Aranki SF, Maisel WH. Development and validation of a simple risk score to predict the need for permanent pacing after cardiac valve surgery. J Am Coll Cardiol. 2003;41:795-801.

5. Leyva F, Qiu T, McNulty D, Evison F, Marshall H, Gasparini M. Long-term requirement for pacemaker implantation after cardiac valve replacement surgery. Heart Rhythm. 2017;14:529-534.

6. Hwang HY, Kim KH, Kim KB, Ahn H. Mechanical tricuspid valve replacement is not superior in patients younger than 65 years who need long-term anticoagulation. Ann Thorac Surg. 2012;93:1154-1160.

7. Rizzoli G, Vendramin I, Nesseris G, Bottio T, Guglielmi C, Schiavon L. Biological or mechanical prostheses in tricuspid position? A meta-analysis of intra-institutional results. Ann Thorac Surg. 2004;77:1607-1614. 
8. Said SM, Burkhart HM, Schaff HV, Johnson JN, Connolly HM, Dearani JA. When should a mechanical tricuspid valve replacement be considered? J Thorac Cardiovasc Surg. 2014;148:603-608.

9. Scully HE, Armstrong CS. Tricuspid valve replacement. Fifteen years of experience with mechanical prostheses and bioprostheses. J Thorac Cardiovasc Surg. 1995;109:1035-1041.

10. Jokinen JJ, Turpeinen AK, Pitkanen O, Hippelainen MJ, Hartikainen JE. Pacemaker therapy after tricuspid valve operations: implications on mortality, morbidity, and quality of life. Ann Thorac Surg. 2009;87:1806-1814.

11. Mar PL, Angus CR, Kabra R, Migliore CK, Goswami R, John LA, Tu Y, Gopinathannair R. Perioperative predictors of permanent pacing and long-term dependence following tricuspid valve surgery: a multicentre analysis. Europace. 2017.

12. Jeganathan $\mathrm{R}$, Armstrong $\mathrm{S}$, Al-Alao B, David $\mathrm{T}$. The risk and outcomes of reoperative tricuspid valve surgery. Ann Thorac Surg. 2013;95:119-124.

13. Jouan J, Mele A, Florens E, Chatellier G, Carpentier A, Achouh P, Fabiani JN. Conduction disorders after tricuspid annuloplasty with mitral valve surgery: Implications for earlier tricuspid intervention. J Thorac Cardiovasc Surg. 2016;151:99103.

14. Brignole M, Auricchio A, Baron-Esquivias G, et al. 2013 ESC guidelines on cardiac pacing and cardiac resynchronization therapy: the task force on cardiac pacing and resynchronization therapy of the European Society of Cardiology (ESC). Developed in collaboration with the European Heart Rhythm Association (EHRA). Europace. 2013;15:1070-1118.

15. Esperer HD, Mahmoud FO, von der Emde J. Is epicardial dual chamber pacing a realistic alternative to endocardial DDD pacing? Initial results of a prospective study. Pacing Clin Electrophysiol. 1992;15:155-161.

16. McLeod CJ, Attenhofer Jost CH, Warnes CA, Hodge D, 2nd, Hyberger L, Connolly HM, Asirvatham SJ, Dearani JA, Hayes DL, Ammash NM. Epicardial versus endocardial permanent pacing in adults with congenital heart disease. J Interv Card Electrophysiol. 2010;28:235-243.

17. Lin G, Nishimura RA, Connolly HM, Dearani JA, Sundt TM, 3rd, Hayes DL. Severe symptomatic tricuspid valve regurgitation due to permanent pacemaker or implantable cardioverter-defibrillator leads. J Am Coll Cardiol. 2005;45:1672-1675. 
18. Delling FN, Hassan ZK, Piatkowski G, Tsao CW, Rajabali A, Markson LJ, Zimetbaum PJ, Manning WJ, Chang JD, Mukamal KJ. Tricuspid Regurgitation and Mortality in Patients With Transvenous Permanent Pacemaker Leads. Am J Cardiol. 2016;117:988-992.

19. Al-Bawardy R, Krishnaswamy A, Bhargava M, Dunn J, Wazni O, Tuzcu EM, Stewart W, Kapadia SR. Tricuspid regurgitation in patients with pacemakers and implantable cardiac defibrillators: a comprehensive review. Clin Cardiol. 2013;36:249-254.

20. Chang JD, Manning WJ, Ebrille E, Zimetbaum PJ. Tricuspid Valve Dysfunction Following Pacemaker or Cardioverter-Defibrillator Implantation. J Am Coll Cardiol. 2017;69:2331-2341.

21. Mazine A, Bouchard D, Moss E, Marquis-Gravel G, Perrault LP, Demers P, Carrier M, Cartier R, Pellerin M. Transvalvular pacemaker leads increase the recurrence of regurgitation after tricuspid valve repair. Ann Thorac Surg. 2013;96:816-822.

22. Eleid MF, Blauwet LA, Cha YM, Connolly HM, Brady PA, Dearani JA, Espinosa RE. Bioprosthetic tricuspid valve regurgitation associated with pacemaker or defibrillator lead implantation. J Am Coll Cardiol. 2012;59:813-818.

23. Sierra J, Rubio J. Transvenous right ventricular pacing in a patient with tricuspid mechanical prosthesis. J Cardiothorac Surg. 2008;3:42.

24. Sharma PS, Subzposh FA, Ellenbogen KA, Vijayaraman P. Permanent His-bundle pacing in patients with prosthetic cardiac valves. Heart Rhythm. 2016;14:59-64.

25. Kemp A, Kjersgaard Johansen J, Kjaergaard E. Malplacement of endocardial pacemaker electrodes in the middle cardiac vein. Acta Med Scand. 1976;199:7-11.

26. Lee ME. Special considerations in ventricular pacing in patients with tricuspid valve disease. Ann Thorac Surg. 1983;36:89-92.

27. Shettigar UR, Loungani RR, Smith CA. Inadvertent permanent ventricular pacing from the coronary vein: an electrocardiographic, roentgenographic, and echocardiographic assessment. Clin Cardiol. 1989;12:267-274.

28. Blackburn ME, Gibbs JL. Ventricular pacing from the coronary sinus of a patient with a Fontan circulation. Br Heart J. 1993;70:578-579.

29. Goldstein DJ, Rabkin D, Spotnitz HM. Unconventional approaches to cardiac pacing in patients with inaccessible cardiac chambers. Ann Thorac Surg. 1999;67:952-958.

30. Rosenthal E, Qureshi SA, Crick JC. Successful long-term ventricular pacing via the coronary sinus after the Fontan operation. Pacing Clin Electrophysiol. 1995;18:21032105 . 
31. Bai Y, Strathmore N, Mond H, Grigg L, Hunt D. Permanent ventricular pacing via the great cardiac vein. Pacing Clin Electrophysiol. 1994;17:678-683.

32. Conti S, Liotta C, Virgilio A, Tamburino C, Calvi V. Left ventricular pacing in a patient with a mechanichal tricuspid prosthesis and high surgical risk. World $\mathbf{J}$ Cardiovasc Dis. 2014;4:567-569.

33. Sideris S, Drakopoulou M, Oikonomopoulos G, Gatzoulis K, Stavropoulos G, Limperiadis D, Toutouzas K, Tousoulis D, Kallikazaros I. Left Ventricular Pacing through Coronary Sinus Is Feasible and Safe for Patients with Prior Tricuspid Valve Intervention. Pacing Clin Electrophysiol. 2016;39:378-381.

34. Touiza A, Etienne Y, Gilard M, Fatemi M, Mansourati J, Blanc JJ. Long-term left ventricular pacing: assessment and comparison with biventricular pacing in patients with severe congestive heart failure. J Am Coll Cardiol. 2001;38:1966-1970.

35. Reddy VY, Exner DV, Cantillon DJ, et al. Percutaneous Implantation of an Entirely Intracardiac Leadless Pacemaker. N Engl J Med. 2015;373:1125-1135.

36. Reynolds D, Duray GZ, Omar R, et al. A Leadless Intracardiac Transcatheter Pacing System. N Engl J Med. 2016;374:533-541.

37. Tang GH, Kaple R, Cohen M, Dutta T, Undemir C, Ahmad H, Poniros A, Bennett J, Feng C, Lansman S. First percutaneous Micra leadless pacemaker implantation and tricuspid valve repair with MitraClip NT for lead-associated severe tricuspid regurgitation. EuroIntervention. 2017;12:e1845-e1848.

38. Kerwin SA, Mayotte MJ, Gornick CC. Transcatheter pacemaker implantation in a patient with a bioprosthetic tricuspid valve. J Interv Card Electrophysiol. 2015;44:8990.

39. Boveda S, Durand P, Combes S, Mariottini CJ. Leadless pacemaker surrounded by three valvular prostheses. Heart Rhythm. 2017;14:1421.

40. Gradaus R, Eckardt L, Wedekind H, Loher A, Bocker D. Transvenous ICD implantation after artificial tricuspid valve replacement. A new approach placing a transvenous ICD lead in the mid cardiac vein of the coronary sinus. Z Kardiol. 2005;94:588-591.

41. Srinivasan NT, Segal OR. Biventricular pacing and coronary sinus ICD lead implantation in a patient with a mechanical tricuspid valve replacement. J Cardiol Cases. 2015:180-182.

42. Lopez JA. Implantable cardioverter defibrillator lead placement in the middle cardiac vein after tricuspid valve surgery. Europace. 2012;14:853-858. 
43. Grimard C, May MA, Mabo P, Babuty D. An original defibrillation lead implantation to avoid tricuspid prosthesis damage. Europace. 2009;12:589-590.

44. Lewis GF, Gold MR. Clinical experience with subcutaneous implantable cardioverterdefibrillators. Nat Rev Cardiol. 2015;12:398-405.

45. Bardy GH, Smith WM, Hood MA, et al. An entirely subcutaneous implantable cardioverter-defibrillator. N Engl J Med. 2010;363:36-44.

46. Burke MC, Gold MR, Knight BP, et al. Safety and Efficacy of the Totally Subcutaneous Implantable Defibrillator: 2-Year Results From a Pooled Analysis of the IDE Study and EFFORTLESS Registry. J Am Coll Cardiol. 2015;65:1605-1615.

47. Weiss R, Knight BP, Gold MR, Leon AR, Herre JM, Hood M, Rashtian M, Kremers M, Crozier I, Lee KL, Smith W, Burke MC. Safety and efficacy of a totally subcutaneous implantable-cardioverter defibrillator. Circulation. 2013;128:944-953.

48. Arias MA, Pachon M, Akerstrom F, Puchol A, Sanchez-Perez A, Rodriguez-Padial L. Subcutaneous Defibrillator: Role in the Prevention of Sudden Cardiac Death in the Setting of Mechanical Tricuspid Prosthesis. Rev Esp Cardiol. 2016;69:343-345.

49. Aris A, Callejo F, Cobiella J, Maestre ML. Tricuspid valve replacement in the presence of an endocardial pacemaker electrode. J Heart Valve Dis. 2004;13:523-524.

50. Molina JE, Roberts CL, Benditt DG. Long-term follow-up of permanent transvenous pacing systems preserved during tricuspid valve replacement. Ann Thorac Surg. 2010;89:318-320.

51. Raman J, Sugeng L, Lai DT, Jeevanandam V. Complex Tricuspid Valve Repair in Patients With Pacer Defibrillator-Related Tricuspid Regurgitation. Ann Thorac Surg. 2016;101:1599-1601. 
466 Table 1: Practical recommendations for patients requiring pacemaker implantation 467 after tricuspid valve surgery.

\begin{tabular}{|c|c|c|c|c|c|c|}
\hline & \multirow{2}{*}{$\begin{array}{l}\text { Immediate } \\
\text { AVB with low } \\
\text { chance of AV } \\
\text { conduction } \\
\text { resumption }\end{array}$} & \multicolumn{5}{|c|}{ Post-operative AVB } \\
\hline & & $\begin{array}{l}\text { Epicardial } \\
\text { leads }\end{array}$ & $\begin{array}{l}\text { RV } \\
\text { transvenous } \\
\text { leads }\end{array}$ & CS leads & $\begin{array}{l}\text { Leadless } \\
\text { PM }\end{array}$ & $\begin{array}{l}\text { His-bundle } \\
\text { pacing }\end{array}$ \\
\hline TV repair & \multirow{3}{*}{$\begin{array}{l}\text { Consider } \\
\text { implanting an } \\
\text { epicardial PM }\end{array}$} & + & ++ & + & $+(*)$ & + \\
\hline TV bioprosthesis & & + & ++ & ++ & $+(*)$ & + \\
\hline $\begin{array}{l}\text { TV mechanical } \\
\text { prosthesis }\end{array}$ & & ++ & 0 & & 0 & 0 \\
\hline
\end{tabular}

$469 *$ after a post-operative blanking period of 1-3 months before considering implantation

472 Table 2: Practical recommendations for patients requiring an implantable cardioverter-

473 defibrillator after tricuspid valve surgery.

\begin{tabular}{|c|c|c|c|c|}
\hline & \multicolumn{4}{|c|}{ Post-operative need for an ICD } \\
\hline & $\begin{array}{l}\text { Epicardial } \\
\text { ICD }\end{array}$ & $\begin{array}{l}\text { RV } \\
\text { transvenous } \\
\text { ICD lead }\end{array}$ & $\begin{array}{ll}\text { CS } & \text { ICD } \\
\text { lead } & \end{array}$ & S-ICD \\
\hline TV repair & + & $+++(*)$ & $0 /+$ & $+++(* *)$ \\
\hline TV bioprosthesis & + & $+++(*)$ & $0 /+$ & $+++(* *)$ \\
\hline TV mechanical prosthesis & $++(*)$ & 0 & $0 /+$ & $+++(* *)$ \\
\hline
\end{tabular}

$475 *$ indication for pacing, ** no indication for pacing 


\section{FIGURES}

478

479

480

481

482

483

484

485

486

487

488

489

490

491

492

493

494

495

496

497

498

499

500

501

502

503

504

505

506

Figure 1: Incidence of a new permanent pacemaker implantation during long-term follow-up after cardiac surgery. Adapted from Leyva et al. ${ }^{5}$ Published with permission of the Publisher.

Figure 2: X-ray showing an epicardial pacemaker after TV (arrow) and mitral valve replacement (panel A) and a dual chamber pacemaker with transvenous leads after TV annuloplasty (arrow, panel B) and TV replacement (arrow, panel C).

Figure 3: LV-pacing only through a CS lead placed in the great cardiac vein in a patient with mechanical TV and mitral valve replacement. Adapted from Conti el al. ${ }^{32}$ Published with permission of the Publisher.

Figure 4: Implantation of Micra leadless pacemaker in two patients with bioprosthetic TV. Adapted from Kerwin SA et $\mathrm{al}^{38}$ and from Boveda S et al. ${ }^{39}$ Published with permission of the Publishers.

Figure 5: ICD implantation after TV surgery. Transvenous lead implantation after TV repair and annuloplasty (arrow, panel A). Implantation of a CS-ICD lead: selective angiography of the coronary sinus in left anterior oblique projection, with mechanical TV and mitral valve; an ICD lead was positioned in the mid-lateral branch of CS (panels B and C, adapted from Srinivasan et $\mathrm{al}^{41}$, Published with permission of the Publisher.). Example of a defibrillation lead positioned with the proximal coil in the inferior vena cava associated with a pacing and sensing lead in the CS (panel D, full and dotted arrow, respectively, adapted from Grimard $\mathrm{C}$ et $\mathrm{al}^{43}$, Published with permission of the Publisher.). Implantation of a subcutaneous ICD in a patient with a mechanical TV (panel E and F, adapted from Arias MA et $\mathrm{al}^{48}$, Published with permission of the Publisher. Copyright (C) 2015 Sociedad Española de Cardiologia. Published by Elsevier Spain, S.L. All rights reserved). 


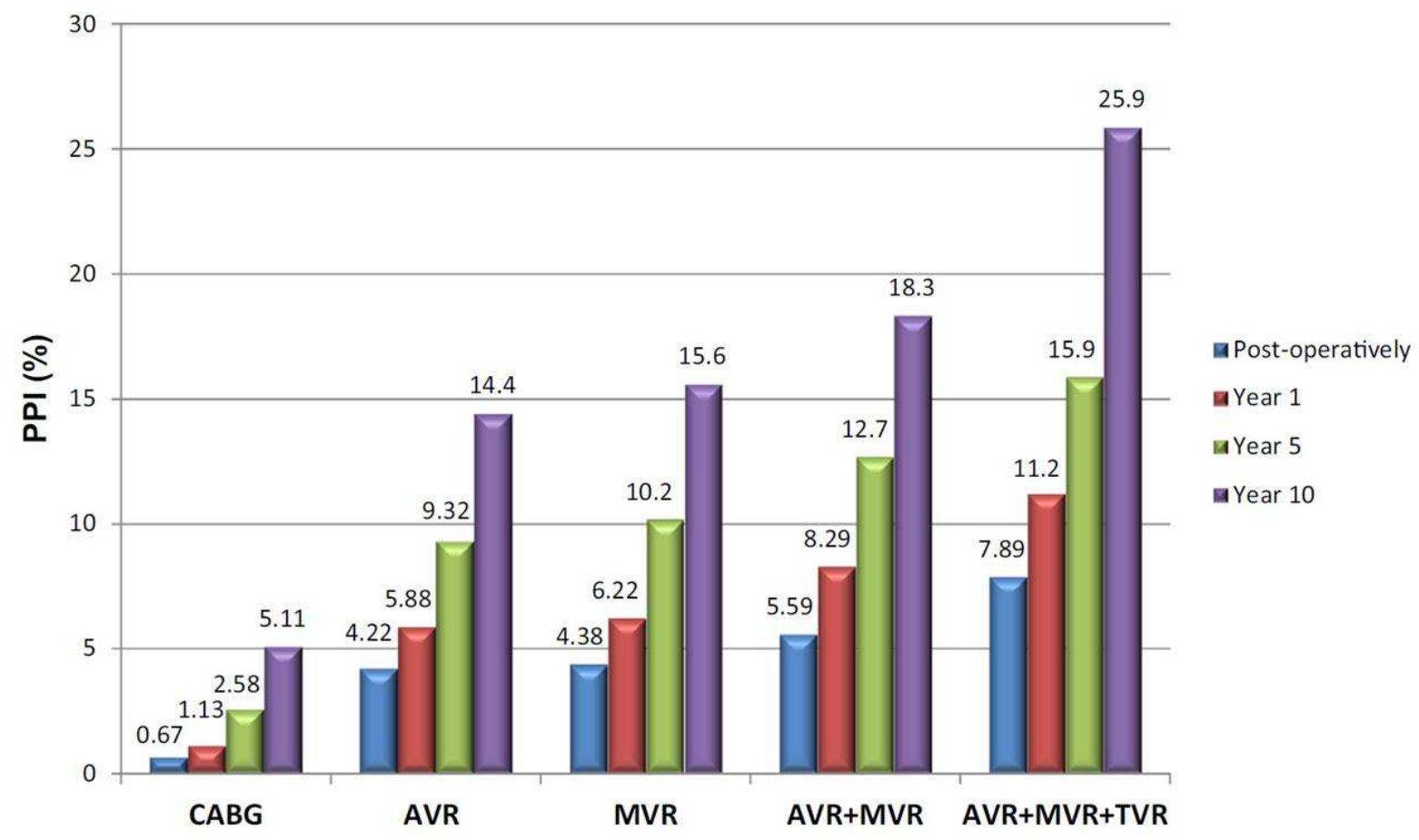




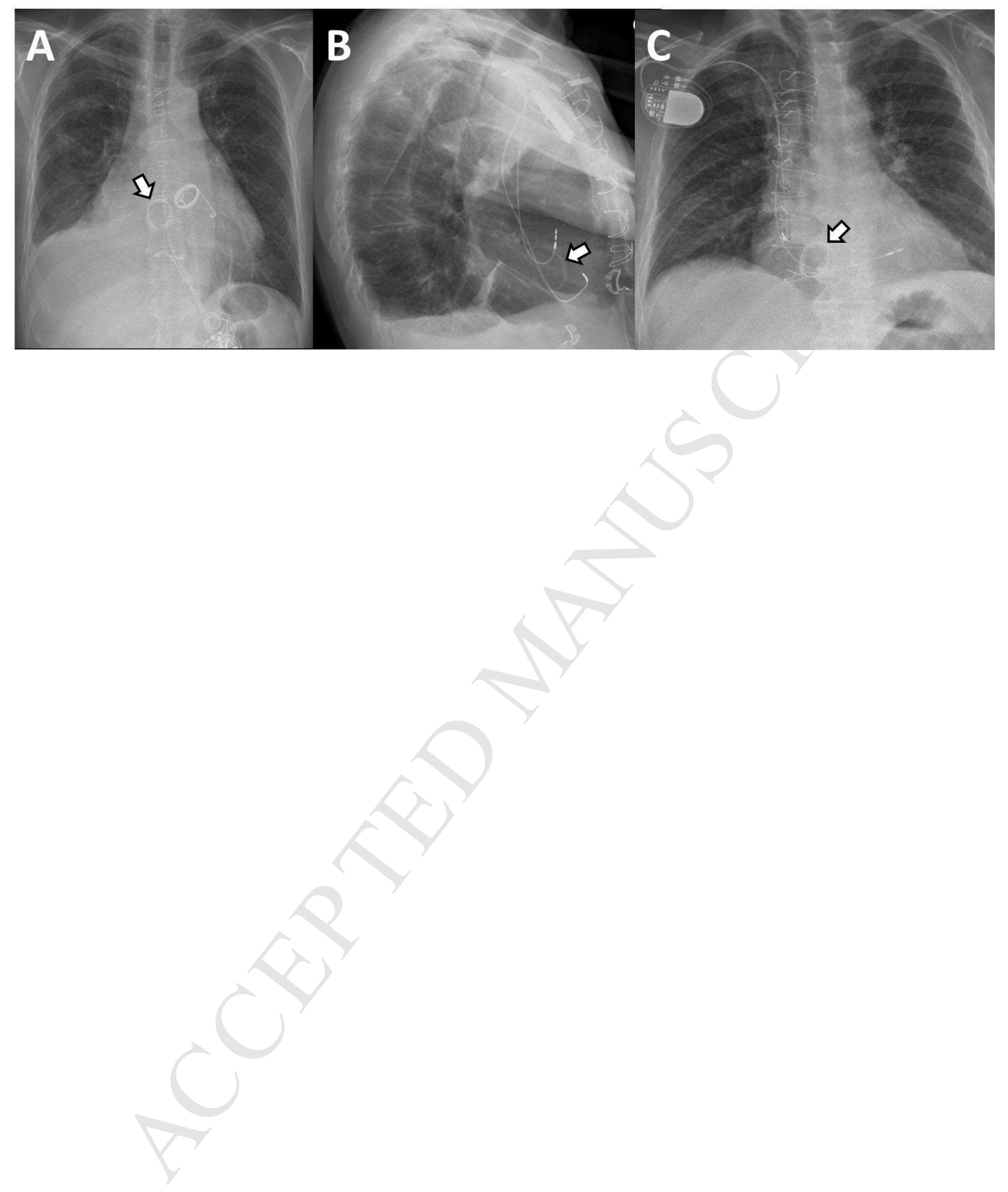




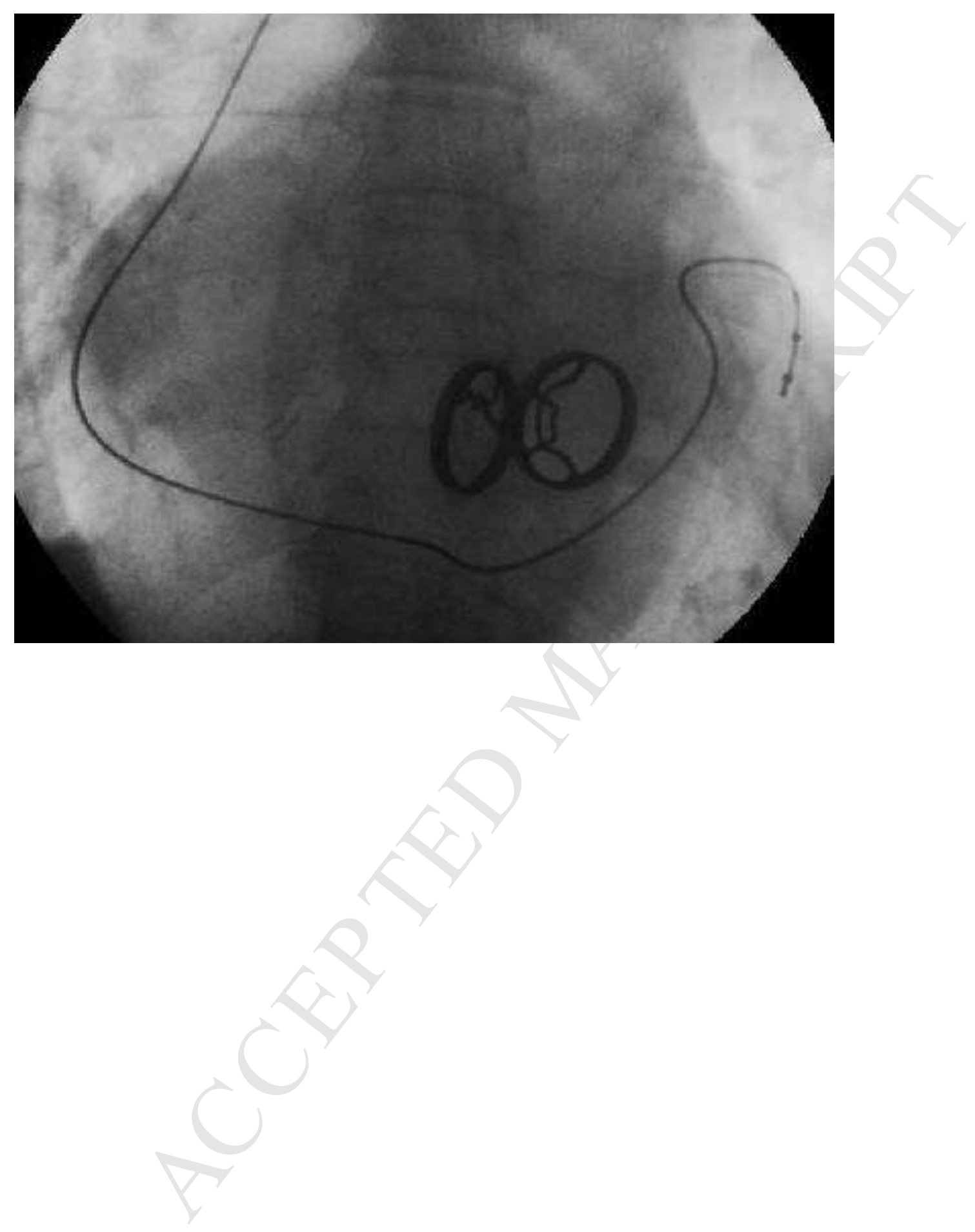



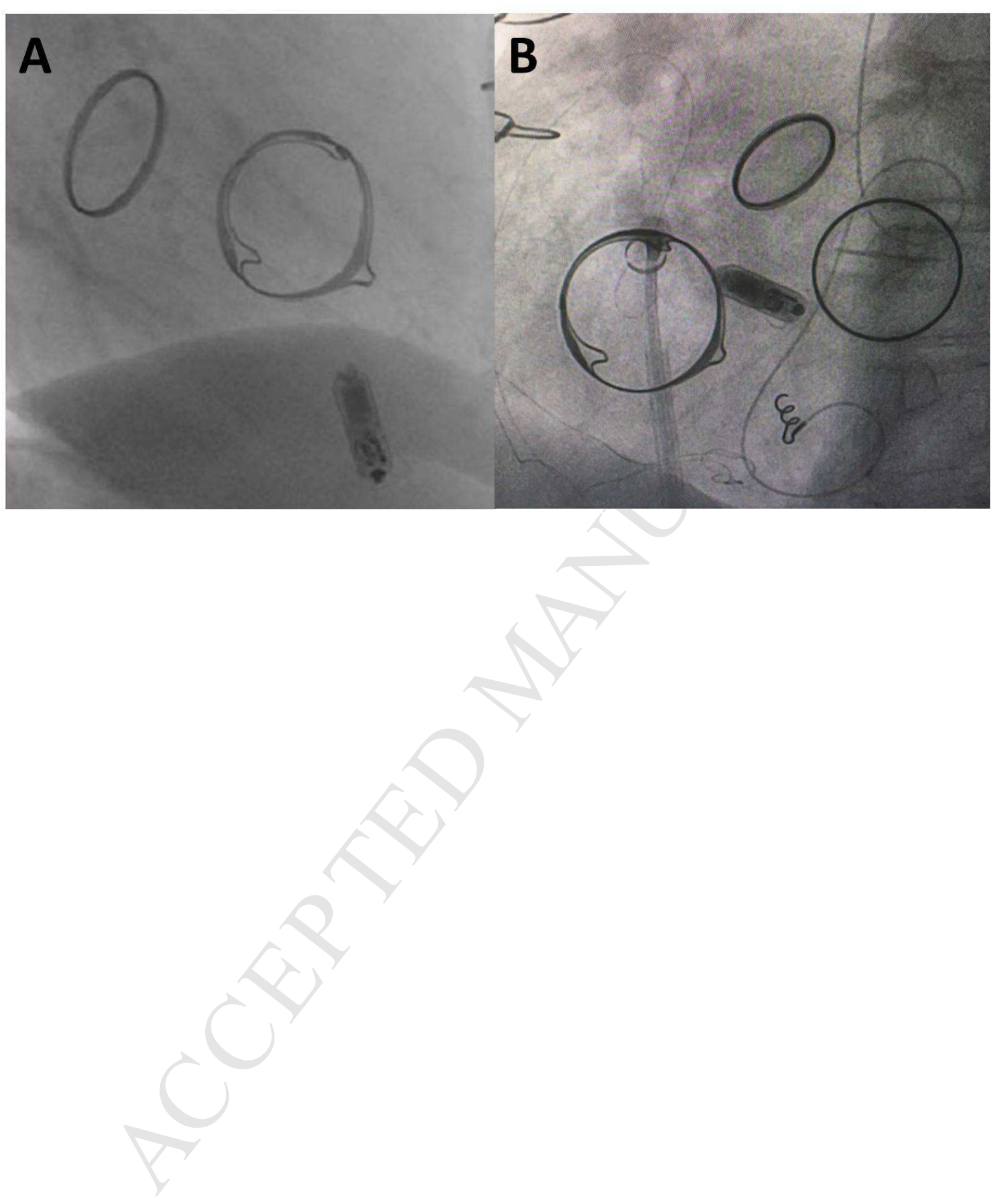


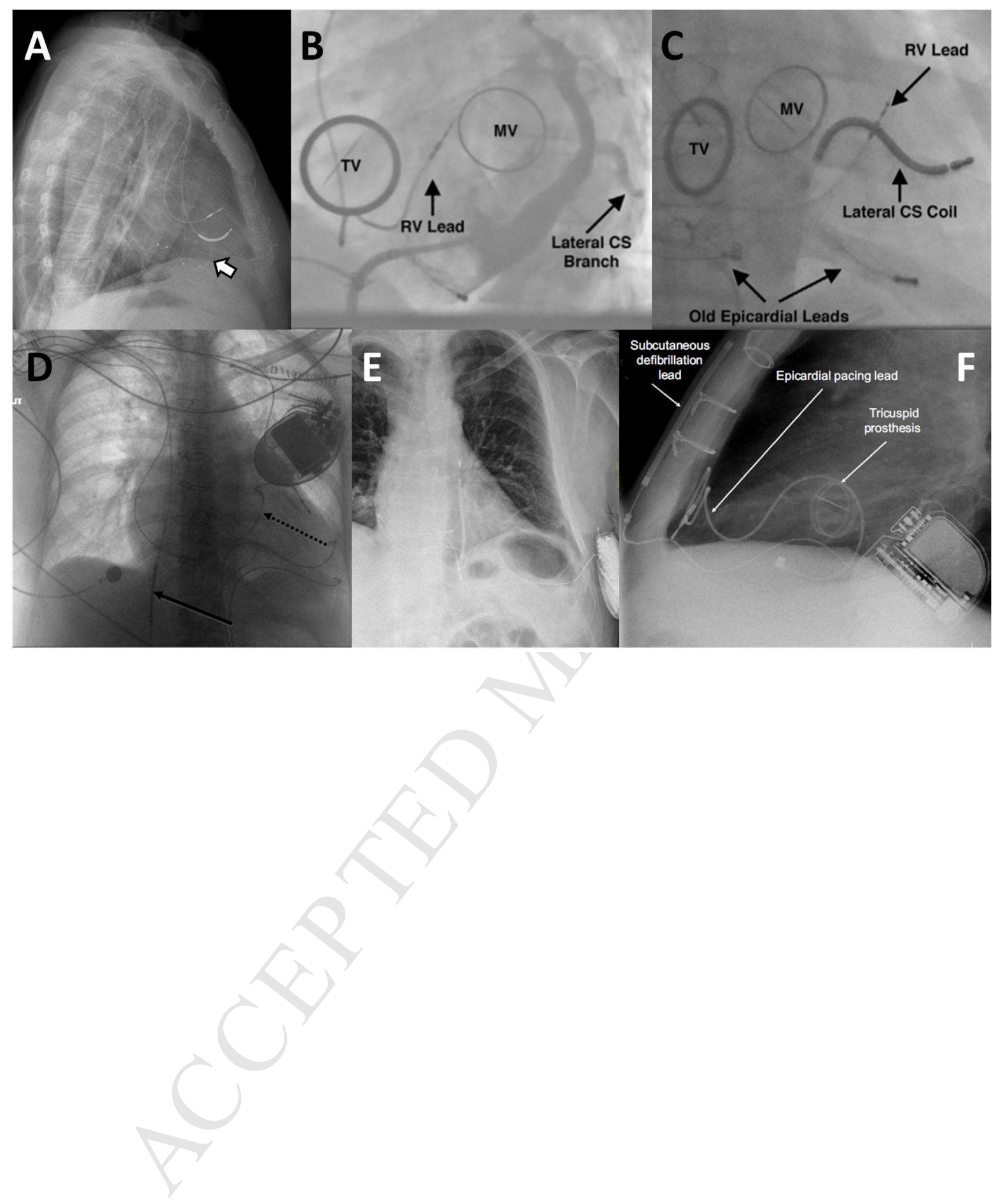

